\title{
Alcohol induces profuse reversible decrease in platelet function and delayed initiation of co-agulation
}

\author{
Alexey Schramko* and Tomi Niemi \\ *Correspondence: alexey.schramko@hus.fi

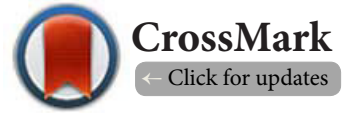

Department of Anesthesiology and Intensive Care Medicine, Helsinki University Central Hospital, Helsinki, Finland.

\begin{abstract}
Moderate alcohol consumption may influence platelet aggregation, reduce fibrinogen concentration or increase clot dissolution. Since the binge-drinking pattern observed among some Northern people leads to exposure of traumatic brain injury and the immediate effects of alcohol on platelet function and whole blood coagulation are partly unknown, we performed an experiment aiming to characterize coagulation capacity during substantial intake of alcohol. A 49-year old volunteer man drank 1 bottle of sparkling wine within one hour: during the first 15 minutes-0.24 L, during the next 15 minutes-0.24 L more, and finally the rest of bottle $(0.27 \mathrm{~L})$ within 30 minutes. Rotational thromboelastometry and platelet function analysis have been performed. Platelet aggregation decreased at 30 minutes, but at 60 minutes the aggregation exceeded the 0 minutes values. Maximum clot firmness remained stable, but clot formation time was prolonged at 30 and 60 minutes. Fibrinolysis has been increased at 30 and 60 minutes. A momentary disturbance of platelet function followed by hyperaggregation, delayed initiation of coagulation and increase in fibrin clot lysis are seen during the early phase of alcohol intake. Since the effects of alcohol may be individual, a combination of detailed history of drinking and point of care evaluation of coagulation and platelet function may shed light on various treatment options in trauma patients on alcohol.
\end{abstract}

Keywords: Alcohol, coagulation, platelet function, thromboelstometry

\section{Introduction}

Moderate alcohol consumption may influence platelet aggregation, reduce fibrinogen concentration or increase clot dissolution [1]. Unfortunately, alcohol intake is a risk factor for traumatic brain injury (TBI). After TBI the development of intracranial haemorrhagic or ischaemic lesions are major determinants of outcome [2] and the risk of bleeding is highest in those patients with inadequate coagulation capacity. Since the binge-drinking pattern observed among some Northern people leads to exposure of TBI and the immediate effects of alcohol on platelet function and whole blood coagulation are partly unknown, we performed an experiment aiming to characterize coagulation capacity during substantial intake of alcohol.

\section{Case presentation}

Methods

After one week total abstinence of alcohol or drugs with theoretical effects on platelets or coagulation, and after 6-hour fast, a 49-year old volunteer man drank in the sitting position 1 bottle $(0.75 \mathrm{~L})$ of cool $\left(+4-6^{\circ} \mathrm{C}\right)$ sparkling wine (2008 Cava Gramona, Brut Nature, Gran Reserva, Catalonia, Spain) within one hour: during the first 15 minutes $-0.24 \mathrm{~L}$, during the next 15 minutes $-0.24 \mathrm{~L}$ more, and finally the rest of bottle $(0.27 \mathrm{~L})$ within 30 minutes.

Ten $\mathrm{ml}$ of venous blood were collected into polypropylene tubes containing EDTA (BD Vacutainer ${ }^{\circledR}$, BD Diagnostics $^{\circledR}$, Ox-ford, UK), 3.2\% sodium citrate, and hirudin (Hirudin Blood Tube, Verum Diagnostica GmbH, Munich, Germany) tubes via a forearm cannula $\left(\mathrm{G} 18, \mathrm{BD}\right.$ Becton, Dickinson $\left.{ }^{\circledR}\right)$ using minimal stasis for haemoglobin concentration $(\mathrm{Hb}, \mathrm{g} / \mathrm{L})$, haematocrit $(\mathrm{Hct}$, $\%)$ and platelet count (x10.9/L), modified thromboelastometry (ROTEM $^{\circledR}$, TEM international, Munich, Germany), as well as for analyses of platelet function (Multiplate ${ }^{\circledR}$, Roche, Basel, Switzerland), respectively. Blood samples were taken before the start of wine intake (0 $\mathrm{min})$, and at 30 (30 $\mathrm{min})$ and 60 minutes (60 min) during the experiment. At the same time intervals, a breath analysis test was performed by alcometer 
(Dräger ${ }^{\circledR}$, Lubeck, Germany) to find out alcohol concentration. Additionally, immediately after sampling the whole blood was diluted with the test wine to make $15 \%$ vol. end-concentration of the wine at room temperature. There after, the samples were analyzed by ROTEM ${ }^{\circledR}$ and Multiplate ${ }^{\circledR}$. The tests of ROTEM $^{\circledR}$ included EXTEM ${ }^{\circledR}$ (extrinsic coagulation pathway) and FIBTEM ${ }^{\circledast}$ (fibrinogen clot) coagulation activators. Platelet function was analyzed with Multiplate ${ }^{\circledR}$ using thrombin reseptor-activating peptide (TRAP), arachidonic acid (ASPI), and adenosine diphosphate (ADP) activators.

\section{Results}

All the coagulation tests were normal before the experiment. Platelet count decreased at 30 and 60 minutes, but $\mathrm{Hb}$ concentration remained unchanged (Table 1). Platelet aggregation (all three activators) decreased at 30 minutes, but at 60 minutes the aggregation exceeded the 0 minutes values. Maximum clot firmness remained stable, but clot formation time was prolonged at 30 and 60 minutes in EXTEM ${ }^{\circledast}$ and FIBTEM $^{\circledR}$ an-alyses (Table 2). Maximum lysis increased in FIBTEM $^{\circledast}$ at

Table 1. Haemoglobin concentration, haematocrit and platelet count, multiplate and results of breath analysis test at study intervals and in vitro with $15 \%$ vol. end-concentration of wine.

\begin{tabular}{lllll}
\hline & 0 min & $\mathbf{3 0}$ min & $\mathbf{6 0}$ min & $\begin{array}{l}\text { 15\% vol. } \\
\text { (in vitro) }\end{array}$ \\
\hline $\mathrm{Hb}$ g/L & 131 & 128 & 128 & 121 \\
$\mathrm{PC}$ & 204 & 152 & 162 & 139 \\
$\mathrm{TRAP}, \mathrm{AUC}$ & 144 & 45 & 174 & 114 \\
$\mathrm{ASPI}, \mathrm{AUC}$ & 109 & 31 & 130 & 64 \\
$\mathrm{ADP}, \mathrm{AUC}$ & 60 & 25 & 91 & 19 \\
Ethanol, \% & 0 & 0.92 & 0.94 & -- \\
\hline
\end{tabular}

Hb: Haemoglobin concentration; PC: Platelet count; TRAP: Thrombin reseptor-activating peptide; ASPI: Arachidonic acid; ADP: Adenosine diphosphate; AUC: Area under curve

Table 2. ROTEM parameters at study intervals, results of breath analysis test and in vitro with $15 \%$ vol. end-concentration of wine.

\begin{tabular}{|c|c|c|c|c|}
\hline & $0 \mathrm{~min}$ & $30 \mathrm{~min}$ & $60 \mathrm{~min}$ & $\begin{array}{l}15 \% \text { vol. } \\
\text { (in vitro) }\end{array}$ \\
\hline \multicolumn{5}{|l|}{ EXTEM } \\
\hline CFT, s & 92 & 106 & 105 & 108 \\
\hline $\mathrm{MCF}, \mathrm{mm}$ & 63 & 59 & 59 & 58 \\
\hline ML, \% & 0 & 5 & 0 & 0 \\
\hline \multicolumn{5}{|l|}{ FIBTEM } \\
\hline $\mathrm{MCF}, \mathrm{mm}$ & 10 & 8 & 11 & 11 \\
\hline ML, \% & 0 & 8 & 25 & 22 \\
\hline Ethanol, \% & 0 & 0.92 & 0.94 & -- \\
\hline
\end{tabular}

CFT: Clot formation time;

MCF: Maximum clot firmness; ML: Maximal lysis
30 and 60 minutes. The alcometer showed 0, 0.92, and $0.94 \%$ at 0,30 , and 60 minutes, respectively. In vitro $15 \%$ vol. endconcentration of wine in the whole blood induced comparable findings with the observations regarding the volunteer.

\section{Discussion}

The present study demonstrates the immediate biphasic character of the coagulation capacity after substantial intake of alcohol in a man. The observations of the collapse of platelet function follows a rebound hyperaggregability with the simultaneous increase in fibrinogen clot dissolution. However, the most important parameter regarding traumatic coagulopathy, clot strength, remained stable although the development of whole blood clot was delayed and clot lysis enhanced.

The current findings may have direct clinical implications in TBI patients if the dynamic history of alcohol intake is known. It may be speculated that there is an increased risk of bleeding if TBl, or other trauma, occurs shortly after the start of drinking. At this phase, the three pathways of platelet activation are depressed by $72 \%$ (ASPI), $58 \%$ (ADP) and 69\% (TRAP). This platelet inhibition is comparable with the combined effects of acetylsalisylic acid, clopidogrel and a glycoprotein-inhibitor on platelets and may be indicative of substantial increase risk of bleeding. However, this platelet dysfunction is short lived and later the platelets hyperaggregated even the alcometer results were unchanged. This finding may also indicate that to become a trauma victim later, i.e., 1 hour, after the start of drinking alcohol may be safer regarding only the platelet function and bleeding risk.

Traumatic hypocoagulopathy is defined by decrease in clot strength [3]. Interestingly, in the current study the clot strength of the volunteer, and also in vitro with the $15 \%$ vol. end-concentration of wine, remained unchanged with simultaneous delay in clot formation. This finding is in accordance with previous studies [3,4], and clinically important, since the present guidelines regarding the treatment of traumatic coagulopathy are based on viscoelastic determination of clot strength. However, an attempt to counteract the particular effect of alcohol on clot formation may not be indicated since the developing clot representing combined function of extrinsic coagulation pathway and platelets (EXTEM), will be finally firm enough. In contrast, early administration of tranexamic acid to correct the increased alcohol induced lysis is supported by our study if a drunk man is a trauma victim, since the early administration of tranexamic acid in TBI or in spontaneous intracranial haematoma patients, prevents the development of intracranial bleeding. In the present observations, FIBTEM $^{\circledast}$ maximum lysis was $8 \%$ at 30 minutes and $25 \%$ at 60 minutes, and in vitro $22 \%$ indicating hyperfibrinolysis which has also been shown to be present in $2.5-7 \%$ of TBI patients [5]. Furthermore, the administration of tranexamic acid is in particular supported by the fact that the FIBTEM ${ }^{\circledR}$ clot strength was at the critical level of $8 \mathrm{~mm}$ 
for bleeding at 30 minutes although the general weakening of clot strength was minimal.

\section{Conclusion}

A momentary disturbance of platelet function followed by hyperaggregation, delayed initiation of coagulation and increase in fibrin clot lysis are seen during the early phase of alcohol intake. Since the effects of alcohol may be individual, a combination of detailed history of drinking and point of care evaluation of coagulation and platelet function may shed light on various treatment options in trauma patients on alcohol.

\section{Competing interests}

The authors declare that they have no competing interests.

\section{Authors' contributions}

\begin{tabular}{|l|c|c|}
\hline Authors' contributions & AS & TN \\
\hline Research concept and design & $\checkmark$ & $\checkmark$ \\
\hline Collection and/or assembly of data & $\checkmark$ & $\checkmark$ \\
\hline Data analysis and interpretation & $\checkmark$ & $\checkmark$ \\
\hline Writing the article & $\checkmark$ & $\checkmark$ \\
\hline Critical revision of the article & $\checkmark$ & $\checkmark$ \\
\hline Final approval of article & $\checkmark$ & $\checkmark$ \\
\hline Statistical analysis & -- & -- \\
\hline
\end{tabular}

\section{Publication history}

Editor: Andrea Biscardi, Maggiore Hospital, Italy.

EIC: Joseph Varon, University of Texas Medical Branch, USA.

Received: 19-Aug-2014 Final Revised: 17-Sep-2014

Accepted: 19-Sep-2014 Published: 26-Sep-2014

\section{References}

1. Harhangi BS, Kompanje EJ, Leebeek FW and Maas Al. Coagulation disorders after traumatic brain injury. Acta Neurochir (Wien). 2008; 150:165-75. | Article | PubMed

2. Harr ME, Heskestad B, Ingebrigtsen T, Romner B, Ronning P and Helseth E. Alcohol consumption, blood alcohol concentration level and guideline compliance in hospital referred patients with minimal, mild and moderate head injuries. Scand J Trauma Resusc Emerg Med. 2011; 19:25. | Article | PubMed Abstract | PubMed Full Text

3. Schochl H, Solomon C, Traintinger S, Nienaber U, Tacacs-Tolnai A, Windhofer C, Bahrami S and Voelckel W. Thromboelastometric (ROTEM) findings in patients suffering from isolated severe traumatic brain injury. J Neurotrauma. 2011; 28:2033-41. | Article | PubMed

4. Engstrom $M$, Schott $U$ and Reinstrup P. Ethanol impairs coagulation and fibrinolysis in whole blood: a study performed with rotational thromboelastometry. Blood Coagul Fibrinolysis. 2006; 17:661-5. | Article I PubMed

5. Maegele M. Coagulopathy after traumatic brain injury: incidence, pathogenesis, and treatment options. Transfusion. 2013; 53 Suppl 1:28S-37S. | Article | PubMed

\section{Citation:}

Schramko A and Niemi T. Alcohol induces profuse reversible decrease in platelet function and delayed initiation of co-agulation. Emerg Med Health Care. 2014; 2:4. http://dx.doi.org/10.7243/2052-6229-2-4 